\title{
ESTUDO DA PRODUÇÃO DE ENERGIA ELÉTRICA A PARTIR DE BIOGÁS COM E SEM PURIFICAÇÃO DE ESTAÇÃO DE TRATAMENTO DE ESGOTO
}

\section{STUDY OF THE ELECTRICITY PRODUCTION FROM BIOGAS WITH AND WITHOUT PURIFICATION FROM SEWAGE TREATMENT STATION}

\author{
G. V. GOMES ${ }^{1}$, S. J. SUDA ${ }^{1}$ A. P. ROSA $^{2}$ e F. A. RODRIGUES ${ }^{1}$ \\ ${ }^{1}$ Universidade Federal de Viçosa, Departamento Química \\ ${ }^{2}$ Universidade Federal de Viçosa, Departamento de Engenharia Agrícola e Ambiental \\ E-mail: gustavo.gomes@ufv.br
}

article info

Article history:

Received 2017-07-07

Accepted 2017-09-0

Available online 2017-11-20
PALAVRAS-CHAVE: Biogás; Aspen HYSYS; Bioenergia; Tratamento de esgoto; Análise econômica.

KEYWORDS: Biogas; Aspen HYSYS; Bioenergy; Sewage treatment station; Economic analysis.

RESUMO: Aterros sanitários e estações de tratamento de esgoto são os principais responsáveis pela produção de biogás, que, quando emitido descontroladamente, pode causar graves problemas ambientais. Uma das formas mais promissoras de aproveitamento desse biogás é a produção de energia elétrica, térmica ou mecânica. Neste estudo foram realizadas simulações com o auxílio do software Aspen HYSYS 28.8 para avaliar os impactos econômicos e energéticos do processo de purificação do biogás em uma planta de produção de energia elétrica. A realização do estudo comparativo considerou duas plantas de produção energética, uma vinculada ao processo de purificação e outra realizando a queima direta do biogás para a produção de eletricidade. O custo associado ao projeto com purificação foi $21 \%$ maior quando comparado ao processo sem purificação. Enquanto o valor mínimo de venda (MSP) foi estimado em 6,59 (US\$/KWh) para o processo de purificação e 0,52 (US\$/KWh) para o processo sem purificação. Foram avaliados também o custo capital e de operação de cada planta, assim como a quantidade de energia elétrica excedente, após suprir as demandas energéticas da estação de tratamento de efluentes (ETE).

\begin{abstract}
Sanitary landfills and sewage treatment plants are most responsible for the production of biogas, which can cause serious environmental problems when emitted uncontrollably. One of the most promising forms of biogas utilization is the generation of electric, thermal or mechanical energy. In this study, the simulator Aspen HYSYS v8.8 software performed the simulations to evaluate economic and energy impact of the biogas purification process at a power plant. The comparative study considered two energy production plants, one linked to the purification process and the other performing the direct burning of biogas aiming to produce electricity. The costs for the purification and non-purification process were US \$17,600,000.00 and US\$ 13,950,000.00, respectively. The minimum selling price (MSP) was estimated at 6.59 (US\$/KWh) for the purification process and 0.52 (US\$/KWh) for the process without purification. The study also evaluated the amount of surplus electricity after meeting the energy demands of the effluent treatment plant (ETE).
\end{abstract}

\section{INTRODUÇÃO}

O crescimento das cidades brasileiras tem influenciado o aumento da produção de esgoto, assim como o crescimento do setor de saneamento, especialmente no que diz respeito 
ao tratamento de esgotos sanitários. Segundo dados do Sistema Nacional de Informações sobre Saneamento (SNIS), 42,7\% de todo o esgoto produzido em 2015 tiveram tratamento, representando um aumento de 1,9 pontos percentuais em relação ao ano anterior (SNIS, 2017). O tratamento de grande parte desses resíduos é realizado em reatores de digestão anaeróbia de fluxo ascendente e manta de lodo, denominados reatores UASB (Upflow Anaerobic Sludge Blanket).

A decomposição anaeróbia dos resíduos orgânicos de estações de tratamento de esgoto (ETEs) e aterros sanitários é responsável pela geração de uma quantidade significativa de lodo e de biogás. O lodo, assim como o biogás, apresenta potencial energético quando desaguado. No entanto, os estudos vinculados à esta área ainda se encontram bastante escassos (Courtaud et al., 2010; De Sena et al., 2007). Segundo o estudo de Fonts et al. (2009) citado por Rosa et al. (2016), o poder calorífico inferior do lodo com teor de umidade $5,3 \%$ é de 7,7 MJ. $\mathrm{kg}^{-1}$, representando um subproduto secundário com potencial energético promissor.

Além do lodo, o biogás também tem se tornado destaque no cenário energético. Sua composição consiste majoritariamente de 70 a $80 \%$ de metano, 10 a $25 \%$ de nitrogênio e 5 a $10 \%$ de dióxido de carbono, além de traços de vapor de água, amônia, ácido sulfídrico e outros hidrocarbonetos. (Noyola et al., 2006; Ryckebosch et al., 2011). Rosa et al. (2016) aponta que o poder calorífico do metano é de 35,9 $\mathrm{MJ} \mathrm{Nm}^{-3}$, enquanto o do biogás com $60 \%$ de metano é de 21,5 MJ.Nm${ }^{-3}$, evidenciando seu elevado potencial calorífico. Dentre os diversos processos utilizados para a produção de energia a partir do biogás, os processos termoquímicos ou de combustões são, em geral, mais utilizados e com maiores eficiências.

O tratamento de gases, especialmente do biogás, é uma etapa necessária antes do início do processo de geração de energia elétrica. De acordo com Deublein et al. (2008), o processo de queima do gás somente se torna viável quando a matéria-prima é livre de qualquer material corrosivo. No entanto, a maior parte do biogás proveniente de aterros sanitários ou de estações de tratamento de esgoto tem concentrações de ácido sulfídrico entre $1.000 \mathrm{a}$ 2.000 ppm em sua composição, o que aumenta a probabilidade de ocorrência de corrosão em tubulações, caldeira e turbinas, reduzindo a vida útil dos equipamentos que compõem a planta (Rosa et al., 2016; Elfattah et al., 2016).

Os métodos de remoção das impurezas (gases ácidos) presentes no biogás, , são classificados em duas categorias: remoção física, que engloba um processo de absorção controlada pelas condições de pressão e temperatura (Loureiro et al., 2006; Yang et al., 2003), às quais o sistema é submetido; e remoção química, que representa o processo de absorção dependente de reações de neutralização ácido-base (Chaemchuen et al., 2016; Sircar et al., 2006; Tock et al., 2010; Vaidya et al., 2007). Segundo Elfattah et al. (2016), em alguns casos, o processo de purificação a que o biogás é submetido favorece a redução combinada de compostos indesejados, como é o caso da remoção conjunta de parte do dióxido de carbono e do ácido sulfídrico durante a etapa de absorção física realizada através do uso de uma solução composta por dietanolamina (DEA) e água. Atualmente, as indústrias de biogás utilizam diversos procedimentos de purificação como remoção química, lavagem 
com água, utilização de membranas, absorção com solventes orgânicos e separação criogênica, como pode ser constado em Chaemchuen et al. (2016).

De acordo com a European Commission (2001), a utilização do biogás com fins energéticos representa uma forma promissora de redução de gases de efeito estufa (GEE). Nesta condição, grande parte do metano, gás 21 vezes mais poluente que o dióxido de carbono, é consumido durante o processo de queima, evitando que seja liberado na atmosfera. Essa situação gera um incentivo à autossuficiência energética de processos industriais. A cogeração de energia representa a produção concomitante de energia térmica e mecânica, a qual pode ser convertida em energia elétrica através de motores ou geradores (Fonseca et al., 2009; Dias, 2011) Segundo Metcalf e Eddy (2003), na maioria dos casos, o montante de energia elétrica produzida através do biogás proveniente da digestão anaeróbia de esgoto doméstico é suficiente para suprir a demanda da planta em operação. Parte da energia elétrica produzida também é consumida no próprio processo de purificação e o excedente, caso ocorra, pode ser comercializado ou reaproveitado para reduzir o custo extra com energia vinculado a outros processos industriais (Rosa et al., 2016).

O crescente interesse pela utilização de energia limpa e renovável e a preocupação com os impactos ambientais acarretados pela emissão de poluentes na atmosfera e pelo descarte inapropriado de resíduos, tem incentivado o desenvolvimento de pesquisas em torno da utilização consciente de dejetos produzidos, principalmente, por aterros sanitários e ETEs. A produção energética a partir de resíduos representa uma iniciativa à redução de problemas ambientais, maximização da eficiência energética e redução de gastos associados a processos industriais ou etapas do tratamento de esgoto. Diante deste cenário, o objetivo do trabalho foi a simulação e análise técnica e econômica da planta de produção de energia elétrica abastecida por biogás proveniente do processo de digestão anaeróbia em reatores UASB.

\section{MATERIAIS E MÉTODOS}

O desenvolvimento deste trabalho foi baseado em dados reais da produção diária de biogás proveniente da ETE, localizada em Itabira (MG). Projetada para atender a demanda de uma cidade de, aproximadamente, 70.000 habitantes e uma vazão máxima de $0,17 \mathrm{~m}^{3} \cdot \mathrm{s}^{-1}$, atualmente opera sob uma vazão média de $0,08 \mathrm{~m}^{3} \cdot \mathrm{s}^{-1}$. Os valores utilizados na simulação foram coletados entre os anos de 2010 e 2011.

De acordo com Rosa et al. (2008) o biogás proveniente do tratamento anaeróbio do esgoto sanitário de Itabira, o qual foi utilizado como matéria-prima na confecção desse trabalho, é composto majoritariamente por uma mistura de metano, nitrogênio e dióxido de carbono, conforme ilustrado na Tabela 1. A presença de amônia, vapor de água, hidrocarbonetos e siloxanos foram desprezadas. Confome verificado na Tabela 1, os limites apresentados encontram-se bem próximos dos definidos por Noyola et al. (2006), que afirma que a fração de metano na composição do biogás deve estar entre 70 e $80 \%$. Os parâmetros operacionais que caracterizam as condições iniciais para o biogás produzido estão apresentados na Tabela 2. 
Tabela 1 - Composição do biogás. Fonte: Rosa et al. (2016).

\begin{tabular}{|c|c|}
\hline Componente & Fração em Volume \\
\hline Metano $\left(\mathbf{C H}_{4}\right)$ & 0,7820 \\
\hline Dióxido de carbono $\left(\mathbf{C O}_{2}\right)$ & 0,0670 \\
\hline Ácido sulfídrico $\left(\mathbf{H}_{2} \mathbf{S}\right)$ & 0,0020 \\
\hline Hidrogênio $\left(\mathbf{H}_{2}\right)$ & 0,0300 \\
\hline Nitrogênio $\left(\mathbf{N}_{2}\right)$ & 0,0990 \\
\hline Oxigênio $\left(\mathbf{O}_{2}\right)$ & 0,0200 \\
\hline
\end{tabular}

Tabela 2 - Condições iniciais de operação. Fonte: Rosa et al. (2016).

\begin{tabular}{|c|c|}
\hline Temperatura (K) & 298,15 \\
\hline Pressão $(\mathbf{k P a})$ & 101,0 \\
\hline Fluxo mássico $\left(\mathbf{m}^{\mathbf{3}} \cdot \mathbf{h}^{-\mathbf{1}}\right)$ & 16,25 \\
\hline
\end{tabular}

\subsection{Softwares utilizados na simulação}

\section{Aspen HYSYS}

As simulações foram realizadas utilizando o software comercial Aspen HYSYS v8.8, disponibilizado pelo Laboratório de Simulação de Processos Químicos (LaSip) do Departamento de Química da Universidade Federal de Viçosa. Este software permitiu uma simulação realista do processo de produção de energia elétrica a partir de resíduos (biogás) provenientes de uma estação de tratamento de efluentes. Os modelos termodinâmicos utilizados nas simulações foram o Acid Gas e o General NRTL (Non-random two-liquid model). O primeiro modelo é utilizado em simulações onde há absorção física de gases ácidos por solventes. O segundo modelo (General NRTL) é uma melhor e mais abrangente opção quando comparado ao modelo NRTL, sendo possível utilizar mais parâmetros de interação binária para melhor representar as interações dos subsistemas binários que constituem a mistura multicomponente.

\section{Concept Draw}

Os diagramas esquemáticos ilustrados no decorrer deste trabalho foram desenvolvidos no software Concept Draw. A utilização desta ferramenta visava exemplificar as propostas de integração energética.

\subsection{Estruturação da proposta de integração energética}

As simulações foram estruturadas em dois cenários distintos para avaliar a influência do processo de purificação na produção energética e para determinar a capacidade de geração de energia elétrica excedente para suprimento da necessidade energética demandada da ETE. No Cenário 1, o biogás, em sua composição original, foi utilizado para alimentar o sistema, 
enquanto no segundo Cenário 2, a matéria-prima foi previamente tratada através do processo absorção utilizando um solvente orgânico (DEA), afim de remover os gases ácidos presentes no biogás. Especificamente no Cenário 2, parte da energia produzida ao final do processo foi utilizada para suprir as demandas energéticas do processo de purificação. Consequentemente, somente a energia remanescente foi disponibilizada como excedente.

Cada um destes cenários foi submetido à duas situações de análise (Hipótese A e B). A Hipótese B foi referente ao processo de conversão total da energia obtida em eletricidade por meio de turbinas e geradores. Por sua vez, a Hipótese A considerou a utilização de parte da energia produzida para secagem prioritária do lodo a um teor de umidade de $10 \%$, e o remanescente de energia foi destinado à produção de eletricidade.

\section{Resultados e discussão}

\subsection{Cenários de produção de energia elétrica a partir do biogás}

Produção de energia elétrica a partir do biogás (Cenário 1)

O Cenário 1 representa o processo de geração de vapor e eletricidade a partir do biogás não purificado, sendo ilustrado pelo diagrama de fluxo de processos (PFD) apresentado na Figura 1. O biogás obtido na ETE foi previamente adequado às condições específicas de temperatura e pressão, conforme expressas na Tabela 3. Este procedimento foi realizado através da associação de um compressor (Compressor) e um resfriador (Cooler 1), permitindo que o gás entrasse no reator (Convertion Reactor), sofrendo combustão juntamente com a corrente de ar. A queima do gás ocorreu na presença de excesso de oxigênio, garantido conversão completa de todos os componentes comburentes. Uma fração dos gases quentes foi perdida para o ambiente (Losses), enquanto a outra fração foi destinada ao fornecimento de calor para vaporização da corrente de água que alimenta a caldeira. O vapor pressurizado produzido no bloco caldeira foi direcionado para quatro turbinas que operam em paralelo, para que obedeçam seus limites de vazão. Essas turbinas são responsáveis pela queda de pressão do vapor, fornecendo energia mecânica ao gerador que, por sua vez, produz energia elétrica.

Tabela 3 - Reator de combustão.

\begin{tabular}{|c|c|c|c|}
\hline Corrente & $\begin{array}{c}\text { Vazão } \\
\left(\mathbf{m}^{\mathbf{3}} \cdot \mathbf{h}^{-\mathbf{1}}\right)\end{array}$ & $\begin{array}{c}\text { Pressão } \\
\mathbf{( k P a )}\end{array}$ & $\begin{array}{c}\text { Temperatura } \\
(\mathbf{K})\end{array}$ \\
\hline Biogas exp & 16,25 & 400 & 298,15 \\
\hline Air & 420 & 101,3 & 298,15 \\
\hline Gases 1 & 431 & 101,3 & 781,35 \\
\hline
\end{tabular}

De acordo com Guzman Mercado (2010), o ácido sulfídrico está presente no biogás em um teor menor do que $1 \%(10.000 \mathrm{ppm})$, no entanto, essa proporção já é considerada prejudicial a caldeiras e turbinas, influenciando em seu tempo de vida útil. A corrosão é considerada baixa até $250^{\circ} \mathrm{C}$, contudo, temperaturas acima de $310^{\circ} \mathrm{C}$ favorecem o processo corrosivo, especialmente em equipamentos de aço carbono, como pode ser constatado em 
Hamaguchi et al. (2009). A composição do biogás estudado apresentou uma concentração de, aproximadamente, 1.653 ppm de ácido sulfídrico. Arias (2010), citado por Guzman Mercado (2010), afirma que caldeiras de aquecimento podem ter seu funcionamento comprometido quando submetidas a concentrações de gases ácidos acima de $1.000 \mathrm{ppm}$. Logo, torna-se necessário a adição de um processo de purificação anterior a combustão.

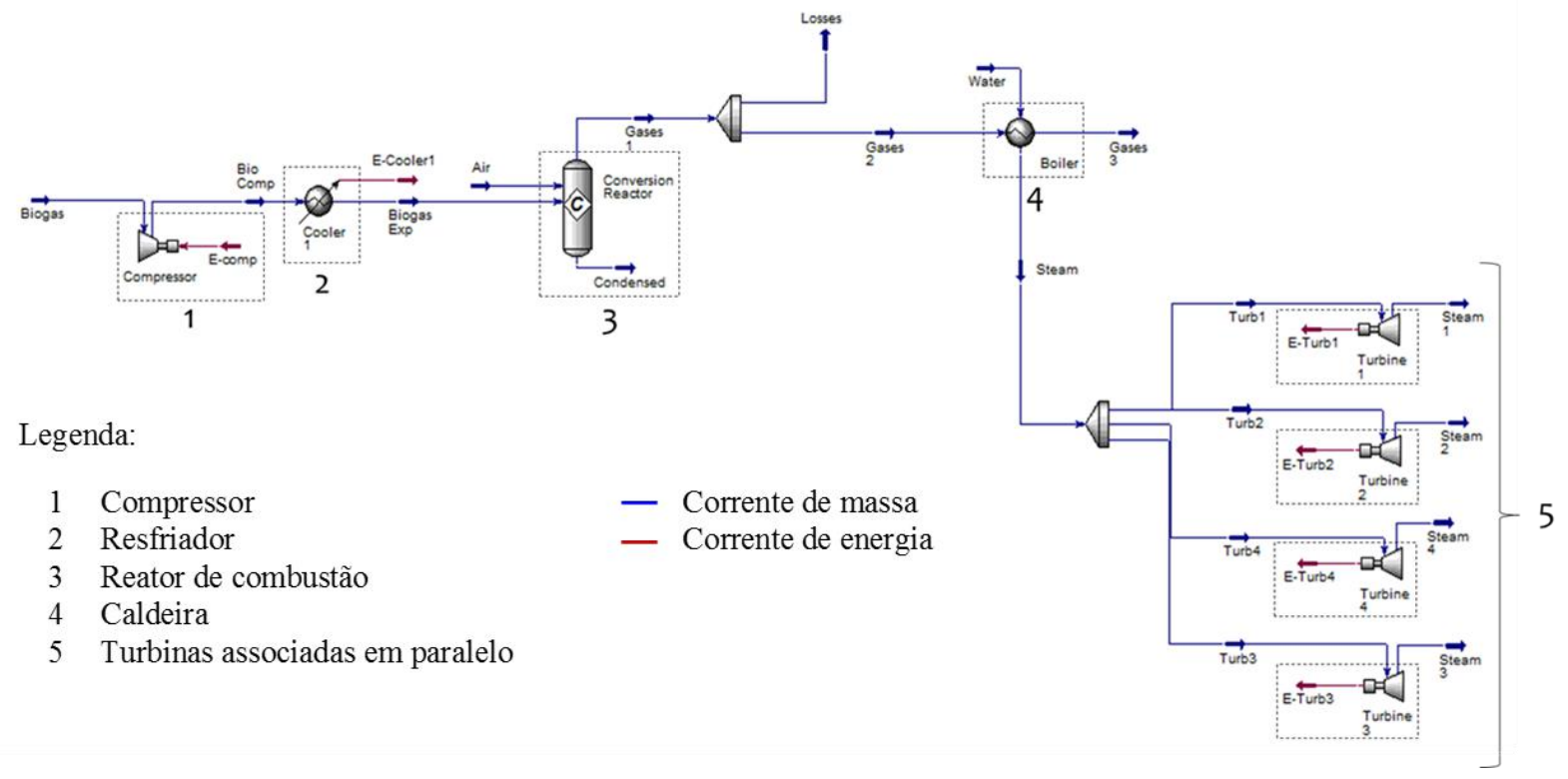

Figura 1 - Diagrama de fluxo do processo sem purificação.

Produção de energia elétrica a partir do biogás purificado (Cenário 2)

O PFD ilustrado na Figura 2 e os dados da Tabela 4 referem-se ao Cenário 2, no qual o biogás foi previamente tratado para a redução do teor ácido sulfídrico a limites toleráveis ao bom desempenho da caldeira e demais equipamentos. O processo utilizado para purificar o biogás favoreceu a remoção conjunta de ácido sulfídrico e dióxido de carbono. A redução de dióxido de carbono na composição da matéria-prima favoreceu o processo de combustão, elevando seu poder calorífico.

A biogás foi comprimido (Compressor) e em seguida resfriado (Cooler 1) para que o gás entrasse na torre de absorção em condições adequadas para obtenção da eficiência máxima no processo. A remoção do ácido sulfídrico e dióxido de carbono foi realizada em uma coluna de absorção (Absorption Column) operando com uma solução de dietanolamina (DEA) a 27,95\% (em volume) em contracorrente com o biogás (Elfattah et al., 2016; Barreau et al., 2006). Dentre os fatores que afetam a eficiência do processo de purificação encontramse a temperatura e pressão de operação da coluna e a concentração do solvente. O biogás com baixo teor de ácido sulfídrico (Free Biogas) foi retirado pelo topo da coluna e encaminhado para o processo de combustão, enquanto a mistura rica em DEA foi obtida no fundo. $\mathrm{Na}$ sequência, o produto de fundo (DEA to Valve) foi despressurizado (Valve 1) e enviado para 
um trocador de calor, no qual a corrente Regen Feed foi aquecida pela corrente de amina regenerada (Regen Bottoms), em um processo de integração energética (Figura 2).

A coluna de destilação foi especificada com 18 estágios, sendo a alimentação feita no estágio 9. A corrente oriunda do trocador de calor foi submetida a uma destilação, na qual obteve-se ácido sulfídrico, dióxido de carbono e água como produto de topo e amina regenerada como produto de fundo. $\mathrm{O}$ ácido sulfídrico extraído do biogás, representa um produto secundário com valor agregado, podendo ser comercializado posteriormente para a indústria de ácido sulfúrico ou podendo ser tratado, evitando assim, sua liberação para atmosfera. No fundo da coluna, obteve-se uma mistura livre dos gases ácidos e contendo o DEA sob condições similares as iniciais. Devido a essa condição, e visando a otimização do processo, essa corrente foi reaproveitada para realimentar a coluna de absorção. No entanto, antes de ser encaminhada à coluna, a amina rica foi resfriada a temperatura inicial para que a eficiência do processo de absorção não seja afetada. Nota-se também a necessidade de um make up para reposição de perdas associadas à etapa de destilação.

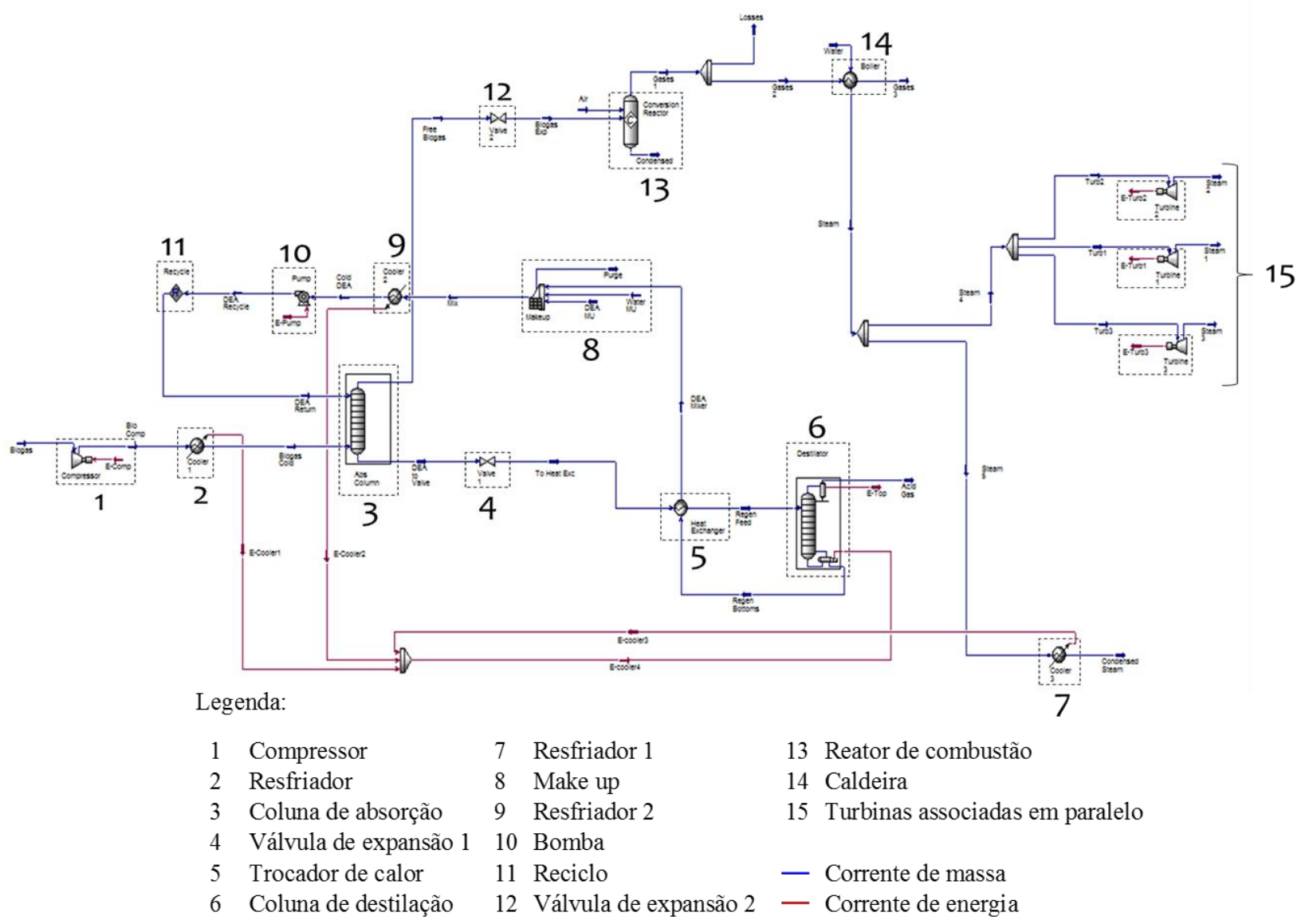

Figura 2 - Diagrama de fluxo do processo com purificação. Adaptado de Elfattah et al. (2016). 
Tabela 4 - Valores das correntes do Cenário 2.

\begin{tabular}{|c|c|c|c|}
\hline & Corrente & $\operatorname{Vazão}\left(m^{3} \cdot h^{-1}\right)$ & Temperatura (K) \\
\hline \multirow{4}{*}{$\begin{array}{c}\text { Coluna de } \\
\text { absorção }\end{array}$} & Biogas Cold & 16,25 & 298,15 \\
\hline & Free Biogas & 15,42 & 278,66 \\
\hline & Rich Amine & 53,75 & 284,20 \\
\hline & DEA Return & 52,91 & 278,31 \\
\hline \multirow{3}{*}{$\begin{array}{l}\text { Coluna de } \\
\text { destilação }\end{array}$} & Regen Feed & 53,75 & 366,15 \\
\hline & Regen Bottoms & 51,39 & 374,65 \\
\hline & Acid Gas & 2,35 & 368,27 \\
\hline \multirow{3}{*}{$\begin{array}{l}\text { Reator de } \\
\text { combustão }\end{array}$} & Biogas Exp & 15,42 & 278,57 \\
\hline & Air & 420,00 & 298,15 \\
\hline & Gases 1 & 430,10 & 779,65 \\
\hline
\end{tabular}

A corrente Free Biogas obtida no topo da coluna de absorção sofreu uma queda de pressão (Valve 2) e seguiu para o reator, no qual foi adicionada uma corrente de ar para desencadear a combustão. Posteriormente, os gases de combustão gerados seguiram para a caldeira (Boiler) com o intuito de fornecer calor para a corrente de água, gerando assim, vapor que, posteriormente, sofreu uma queda de pressão nas turbinas, fornecendo energia mecânica para o gerador que produzirá a energia elétrica.

Visando a otimização do projeto, parte da energia liberada no processo foi reaproveitada em outras etapas através de uma integração energética. A energia liberada durante o resfriamento da corrente de amina regenerada (Regen Bottoms - Cooler 2) e do biogás (Biogas Cold - Cooler 1) foram utilizadas para suprir parte da energia demandada pelo refervedor (Reboiler). O complemento energético foi suprido por parte do vapor gerado na caldeira, evitando um gasto extra desnecessário de energia.

\subsection{Alternativas para aproveitamento energético do lodo e do biogás}

O lodo, produto secundário obtido na digestão anaeróbia do esgoto, quando associado ao biogás pode representar alternativa promissora de potencializar a produção de energia elétrica. Nessas condições foram analisadas duas situações distintas em cada um dos cenários apresentados no tópico 3.1 A Hipótese A prioriza a secagem do lodo e converte em eletricidade somente a energia remanescente, ao passo que Hipótese B considera a conversão total da energia mecânica em eletricidade. 
Secagem prioritária do lodo e conversão do excedente em energia elétrica (Hipótese A)

O lodo proveniente da ETE apresenta umidade de 58,7\% e poder calorífico inferior de 2,0 MJ.kg-1 estando abaixo do reportado por Fonts et al. (2009) que é de 7,7 MJ.kg-1 para um lodo com umidade de 5,3\%. Baseando-se na condição inicial do lodo, é perceptível a necessidade de um processo de secagem da matéria-prima. Para a Hipótese A apresentada nas Figuras 3 e 4, definiu-se o limite de umidade final em 10\% e o processo de secagem é como atividade prioritária em relação à produção de eletricidade. Dessa forma, parte da energia produzida foi utilizada para suprir a demanda do secador e o excedente foi utilizado para

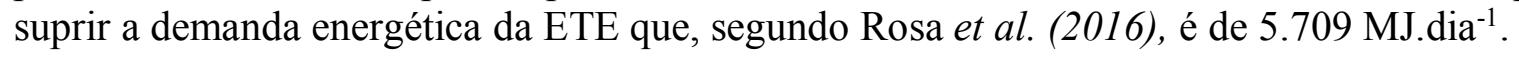

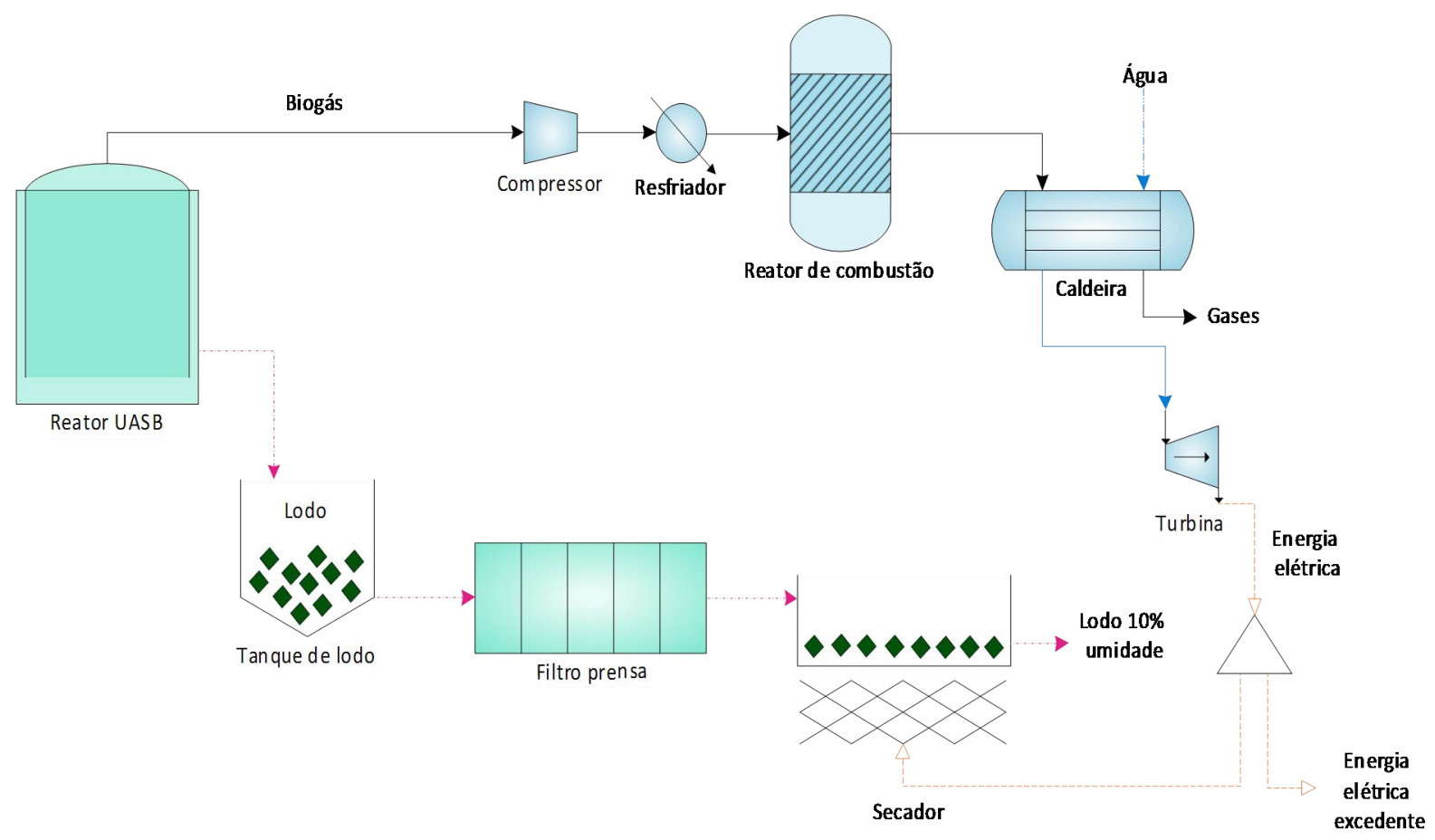

Figura 3 - Diagrama esquemático do uso da energia elétrica proveniente do processo sem purificação (Cenário 1) destinado à secagem prioritária do lodo (Hipótese A).

A Figura 4 representa detalhadamente o processo de produção de energia elétrica. $\mathrm{O}$ processamento se inicia com a digestão anáerobia do efluente em reatores UASB para a obtenção do biogás e do lodo. Para a Hipótese A o lodo digerido foi enviado para um filtro prensa, visando a eliminação de uma parte da água nele retida ao término do processo anterior. Em seguida, foi direcionado a secadores onde ocorrerá a vaporização da água remanescente até que o material se encontre a uma umidade de $10 \%$. Toda a energia elétrica utilizada na secagem foi proveniente do processo de queima do biogás, portanto, não foi necessária nenhuma fonte externa abastecendo o sistema, tornando-o autossuficiente em termos energéticos. 
O processo retratado na Figura 4 é similar ao apresentado na Figura 3, no entanto, o principal diferencial foi o processo de purificação que o biogás é submetido antes de ser encaminhado para o reator de combustão. No contexto da planta de purificação (Cenário 2), parte do vapor produzido pela caldeira foi destinado ao refervedor da coluna de destilação e parte da energia elétrica final foi utilizada para suprir a demanda energética do secado, visando, mais uma vez, a autossuficiência do processo. Dessa forma, garantiu-se que o processo funcionasse sob sua eficiência máxima e que toda a energia produzia ao término de processamento do biogás foi excedente, podendo ser reutilizada em outras atividades ou comercializada.

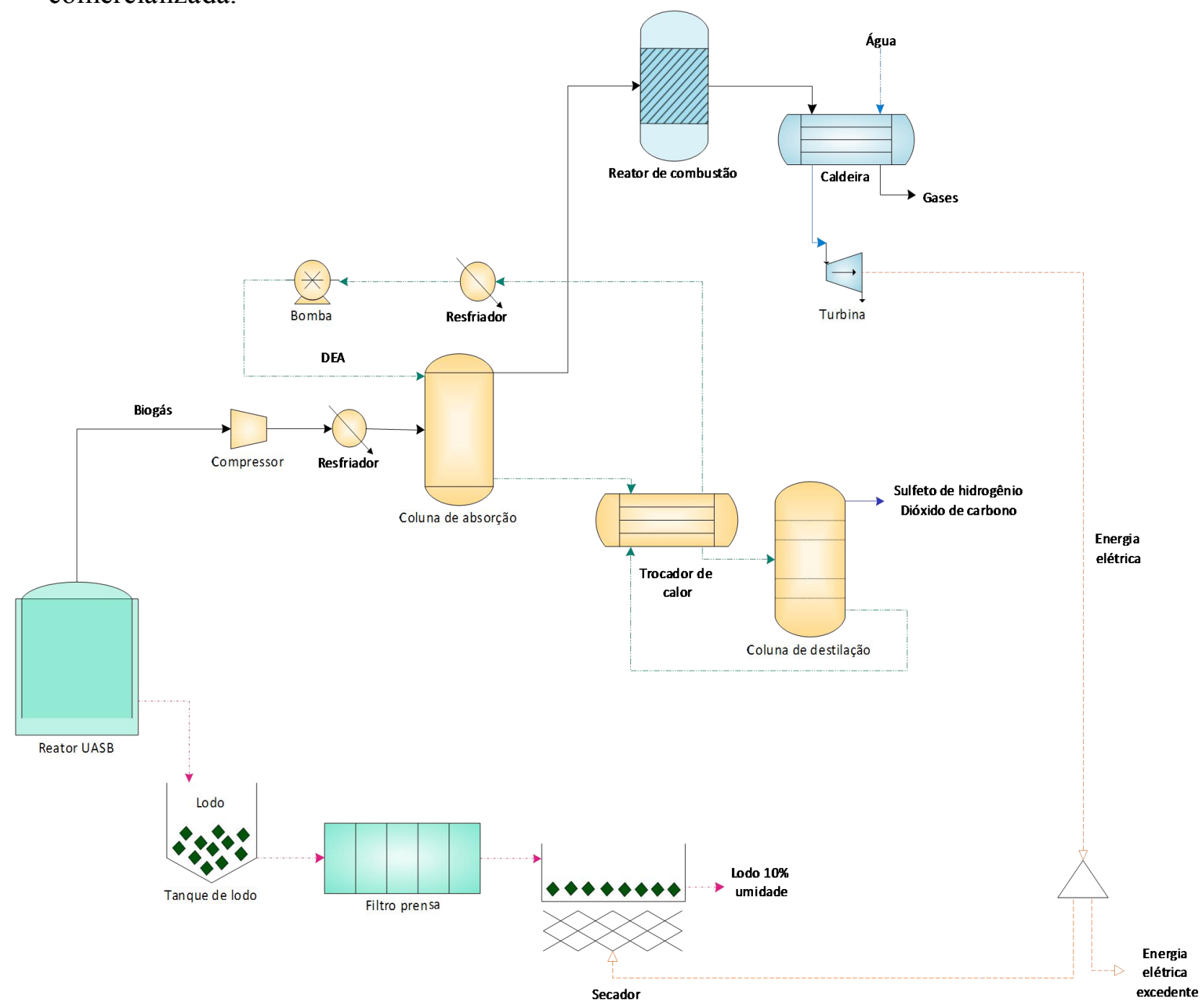

Figura 4 - Diagrama esquemático do uso da energia elétrica proveniente do processo com purificação (Cenário 2) destinado à secagem prioritária do lodo (Hipótese A). 


\section{Conversão total em energia elétrica (Hipótese B)}

A Hipótese B utiliza a mesma matéria-prima da Hipótese A, compartilhando a mesma composição, vazão e temperatura inicial. Todavia, para esta Hipótese B, o biogás obtido foi encaminhado diretamente à produção de eletricidade, desprezando quaisquer gastos inciais com a secagem prévia do lodo (Figuras 5 e 6). A vazão diária total do material produzido nos reatores UASB foi enviada, separadamente, para cada um dos cenários descritos no tópico 3.1. Para cada um dos cenários, a disponibilidade energética varia de acordo com as condições de operação da planta, o que permite um estudo comparativo da eficiência energética associada a cada processo, assim como avaliar se ocorrerá produção de excedente ou não.

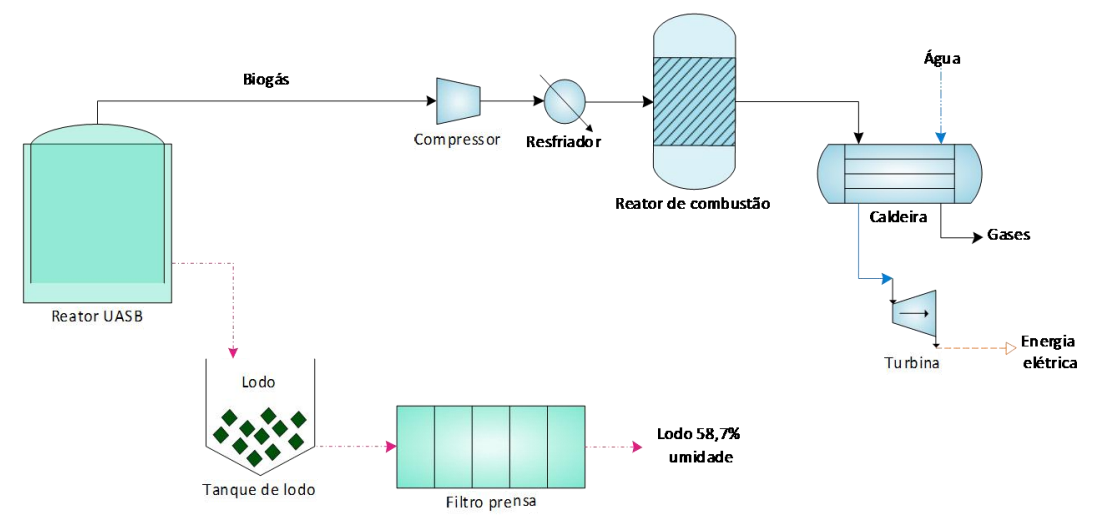

Figura 5 - Diagrama esquemático da produção de energia elétrica do processo sem purificação (Cenário 1) sem a secagem do lodo (Hipótese B).

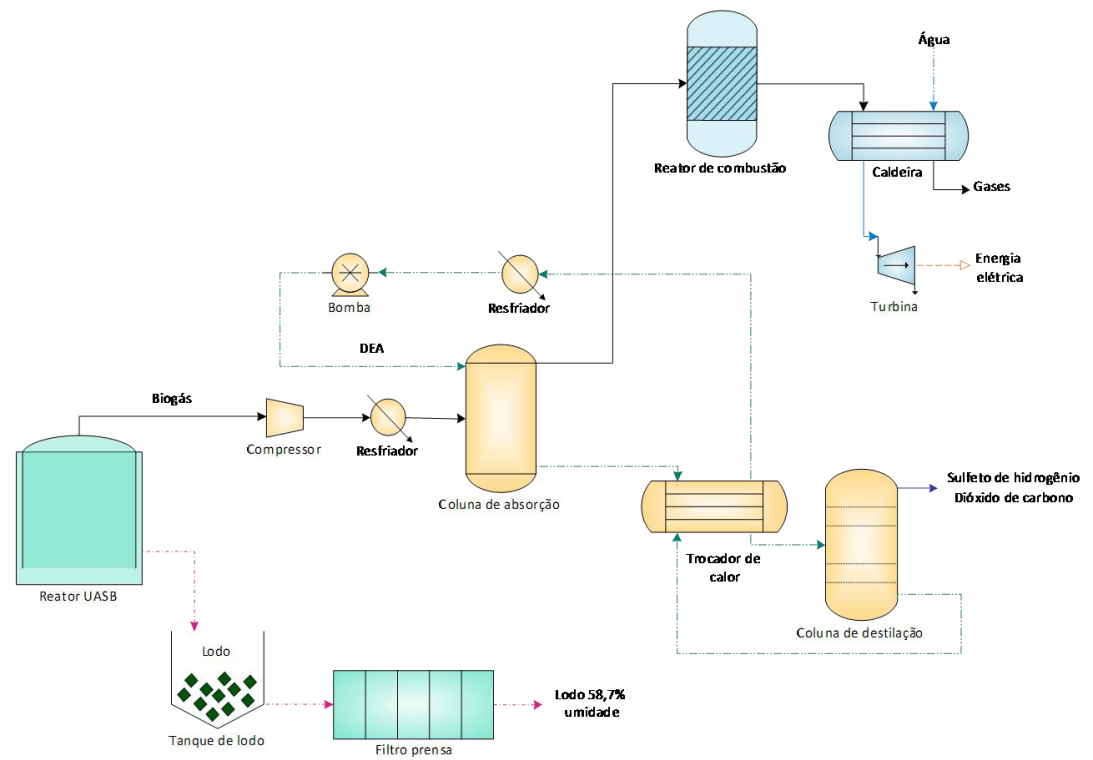

Figura 6 - Diagrama esquemático da produção de energia elétrica do processo com purificação (Cenário 2) sem a secagem do lodo (Hipótese B). 


\subsection{Eficiência de purificação do Cenário 2}

Incialmente, o biogás foi adicionado ao sistema de purificação à uma concentração de $1.653 \mathrm{ppm}$ de ácido sulfídrico. Após o processo de absorção com uma solução de DEA, esta concentração foi reduzida a 5,80 ppm, representando uma eficiência de remoção de $99,65 \%$ de ácido sulfídrico. De acordo com o limite proposto por Guzman Mercato (2010), um dos requisitos necessários para processamento de gases em caldeiras é que o teor de $\mathrm{H}_{2} \mathrm{~S}$ seja inferior a $1.000 \mathrm{ppm}$. Portanto, nestas condições o procedimento de purificação, na temperatura e pressão determinados para a simulação, encontrou-se dentro dos limites apresentados na literatura, representando apenas 1,94\% do seu valor máximo.

O processo de absorção utilizando um solvente orgânico com aminas, a exemplo do DEA, é uma das tecnologias predominantes na remoção de gases ácidos, especialmente por apresentar potencial de remoção combinada de ácido sulfídrico e dióxido de carbono, e possibilidade de regeneração (Guzman Mercado, 2010). Baseando-se na simulação do Cenário 2, além da remoção primária do gás ácido (ácido sulfídrico), também houve decréscimo de cerca de $71,45 \%$ de dióxido de carbono na linha purificada, conforme pode ser verificado na Tabela 5.

Tabela 5 - Percentual de remoção de compostos após o procedimento de purificação.

\begin{tabular}{|c|c|c|c|}
\hline & $\begin{array}{c}\text { Biogas } \\
\left(\mathbf{m}^{\mathbf{3}} \cdot \mathbf{h}^{-\mathbf{1}} \mathbf{)}\right.\end{array}$ & $\begin{array}{c}\text { Free Biogas } \\
\left(\mathbf{m}^{\mathbf{3}} \cdot \mathbf{h}^{-\mathbf{1}} \mathbf{)}\right.\end{array}$ & $\begin{array}{c}\text { Percentual de remoção } \\
\text { após a purificação } \mathbf{~} \mathbf{0})\end{array}$ \\
\hline Metano $\left(\mathbf{C H}_{\mathbf{4}}\right)$ & 12,66 & 12,61 & 0,4 \\
\hline Dióxido de carbono $\left(\mathbf{C O}_{\mathbf{2}}\right)$ & 1,08 & 0,31 & 71,5 \\
\hline Ácido sulfídrico $\left(\mathbf{H}_{\mathbf{2}} \mathbf{S}\right)$ & 0,01 & $\sim 0$ & 99,7 \\
\hline Hidrogênio $\left(\mathbf{H}_{\mathbf{2}}\right)$ & 0,56 & 0,55 & 0,2 \\
\hline Nitrogênio $\left(\mathbf{N}_{\mathbf{2}}\right)$ & 1,61 & 1,61 & 0,1 \\
\hline Oxigênio & 0,33 & 0,33 & 0,3 \\
\hline
\end{tabular}

\subsection{Eficiência energética}

Neste trabalho foram analisados dois tipos de cenários (1 e 2) sob duas hipóteses (A e B) diferentes, visando determinar a eficiência energética de cada caso e realizar uma análise comparativa dos resultados obtidos. O método comparativo baseou-se em fixar uma determinada hipótese e avaliar o resultado obtido para cada um dos respectivos cenários. Os dados também foram confrontados com os obtidos no artigo de Rosa et al. (2016).

\section{Comparação energética entre os cenários vinculados a Hipótese A}

De acordo com Rosa et al. (2016), o monitoramento de consumo energético da ETE Laboreaux durante o período de 2010-2011, indicou que seu funcionamento demandava

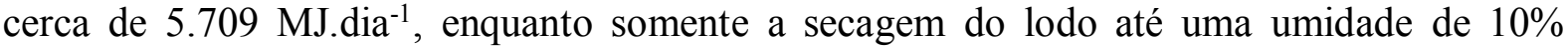

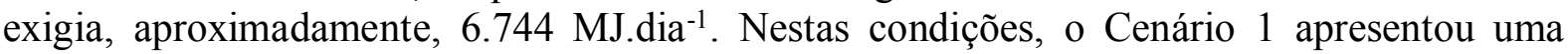


produção energética elevada, sendo capaz de produzir um excedente de energia elétrica de 65.715 MJ.dia $^{-1}$, mesmo após a secagem do lodo. O mesmo é verificado para o Cenário 2, todavia o excedente de energia elétrica foi relativamente menor $\left(2.149 \mathrm{MJ}^{\left.-d_{i}{ }^{-1}\right)}\right.$ que o do Cenário 1 (Tabela 6).

A energia útil total considera que o sistema é autossustentável, portanto, considera somente a energia excedente após suprir as necessidades energéticas de equipamentos do sistema, como bombas e compressores que utilizam energia elétrica para seu funcionamento. Quando necessário, também ocorre integração energética (Cenário 2), visando eliminar a necessidade de fontes externas de vapor e eletricidade. Portanto, a energia útil é referente a capacidade energética obtida ao final de cada cenário.

Tabela 6 - Comparação energética dos Cenários 1 e 2, considerando a Hipótese A.

\begin{tabular}{|c|c|c|c|c|}
\hline & \multicolumn{2}{|c|}{ Cenário 1 } & \multicolumn{2}{c|}{ Cenário 2 } \\
\hline & Valores & $\begin{array}{c}\text { Percentual } \\
\text { energético (\%) }\end{array}$ & Valores & $\begin{array}{c}\text { Percentual } \\
\text { energético (\%) }\end{array}$ \\
\hline $\begin{array}{c}\text { Energia útil total (MJ.dia-1 } \\
\text { Energia para secagem do } \\
\text { lodo (MJ.dia }\end{array}$ & 78.168 & - & 14.602 & - \\
\hline $\begin{array}{c}\text { Energia demandada pela } \\
\text { ETE (MJ.dia- }\end{array}$ & 6.744 & 9 & 6.744 & 46 \\
\hline $\begin{array}{c}\text { Energia elétrica excedente } \\
\text { (MJ.dia }^{-1} \text { ) }\end{array}$ & 5.709 & 7 & 5.709 & 39 \\
\hline
\end{tabular}

Conforme evidenciado a Tabela 6 , ambos cenários apresentaram uma produção excedente de eletricidade de $84 \%$ e $15 \%$ para os cenários 1 e 2 , respectivamente. Baseandose nestes dados, fica evidenciado que o processo de purificação o biogás acarretou uma redução da produção energética, especialmente quando comparado ao cenário onde ocorreu combustão completa do material. O Cenário 1 apresentou maior produção energética devido a presença de ácido sulfídrico, que ao sofrer combustão liberou energia para o meio, fazendo com que a temperatura de saída dos gases quentes elevasse em cerca de 274,7 K. A temperatura de saída mais alta favoreceu o aumento da vazão de vapor da caldeira (Boiler) e, consequentemente, a produção de energia elétrica. Nesta análise, o Cenário 1 representaria uma condição ideal de queima, no qual todo o material é consumido. Entretanto, esse procedimento, na prática, não é viável, devido a presença de composto altamente nocivos ao sistema, sendo necessária uma purificação inicial.

\section{Comparação energética entre os cenários vinculados a Hipótese B}

A Tabela 7 apresenta os valores percentuais de produção excedente de energia elétrica em ambos os cenários, sendo considerado somente os gastos vinculados à demanda energética diária da ETE e os gastos referentes ao processo de purificação (bombas e 
compressores). Dessa forma, o Cenário 1 se destacou novamente em relação ao outro, apresentando um excedente de energia $88 \%$ maior que o Cenário 2 . Nessas condições, o Cenário 1 seria apto a fornecer, aproximadamente, doze vezes a demanda energética da ETE diária, enquanto o outro cenário seria capaz de suprir uma única vez.

Tabela 7 - Comparação energética dos Cenários 1 e 2, considerando a Hipótese B.

\begin{tabular}{|c|c|c|c|c|}
\hline & \multicolumn{2}{|c|}{ Cenário 1 } & \multicolumn{2}{|c|}{ Cenário 2 } \\
\hline & Valores & $\begin{array}{c}\text { Percentual } \\
\text { energético (\%) }\end{array}$ & Valores & $\begin{array}{c}\text { Percentual } \\
\text { energético (\%) }\end{array}$ \\
\hline $\begin{array}{c}\text { Energia útil total } \\
\text { (MJ.dia-1) }\end{array}$ & 78.168 & - & 14.602 & - \\
\hline $\begin{array}{c}\text { Energia demandada } \\
\text { pela ETE (MJ.dia-1) }\end{array}$ & 5.709 & 7 & 5.709 & 39 \\
\hline $\begin{array}{c}\text { Energia elétrica } \\
\text { excedente (MJ.dia-1) }\end{array}$ & 72.459 & 93 & 8.893 & 61 \\
\hline
\end{tabular}

Apesar do alto potencial energético associado ao processo sem purificação, o custo de com manutenção e troca de equipamentos iria reduzir o custo-benefício associado ao projeto, devido ao dano causado pela alta concentração de ácido sulfídrico. Além disso, a energia excedente possui baixo valor agregado, reduzindo as possibilidades de viabilização do funcionamento da planta sem purificação. Contudo, o Cenário 2 representou uma situação mais otimista, no qual o processo de degradação dos equipamentos e tubulações é reduzido drasticamente devido ao processo de remoção do ácido sulfídrico, favorecendo a implantação deste projeto.

\subsection{Análise econômica}

A análise econômica do projeto é de vital importância, por permitir a obtenção de informações como o custo capital total e o custo de operação. A partir destas informações torna-se possível a identificação dos parâmetros que mais afetam o custo final do projeto, permitindo uma ação mais precisa na redução de gastos. Esta avaliação é de suma importância por considerar o valor de investimento inicial e as despesas associadas ao funcionamento da planta, os quais podem indicar a inviabilização do projeto.

Custo de investimento

O custo total de investimento foi de US\$ 17.600.000,00 e US\$13.950.000,00 para o processo com purificação (Cenário 2) e sem purificação (Cenário 2), respectivamente. Os custos de investimentos para cada um dos cenários estão descritos na Tabela $8 . \mathrm{O}$ 
levantamento do valor total investido considera somente as plantas representadas pelos cenários 1 e 2 avaliados, excluindo todo e qualquer custo associado ao processo de digestão anaeróbia para obtenção do biogás.

Tabela 8 - Custo de investimento.

\begin{tabular}{|c|c|c|}
\hline Elemento & Cenário 1 (US\$) & Cenário 2 (US\$) \\
\hline Compra do Equipamento & $5.258 .600,00$ & $5.850 .000,00$ \\
\hline Instalação do equipamento & $53.250,70$ & $61.007,90$ \\
\hline Tubulação & $1.396 .620,00$ & $1.850 .000,00$ \\
\hline Pessoal & $108.652,00$ & $162.429,00$ \\
\hline Aço & - & $25.305,50$ \\
\hline Instrumentação & $825.428,00$ & $1.060 .000,00$ \\
\hline Elétrico & $729.319,00$ & $834.348,00$ \\
\hline Isolamento & $159.016,00$ & $201.309,00$ \\
\hline Pintura & $12.377,80$ & $31.029,2$ \\
\hline Outros & $3.314 .200,00$ & $4.820 .000,00$ \\
\hline Taxas de Contrato & $440.918,00$ & $591.443,00$ \\
\hline Geral e Administração & $309.956,00$ & 378.596 \\
\hline Contingências & $2.269 .500,00$ & $2.860 .000,00$ \\
\hline Total & $14.877 .800,00$ & $18.726 .000,00$ \\
\hline Custo total ajustado & $13.950 .000,00$ & $17.600 .000,00$ \\
\hline
\end{tabular}

O Cenário 2 envolveu uma maior diversidade e quantidade de operações unitárias, fator altamente influenciado pelo processo de purificação, o que elevou o valor inicial de investimento em, aproximadamente, US\$ 3.650.000,00. Este valor reflete um aumento de $21 \%$ do Cenário 2 em relação ao Cenário 1, sendo os custos com equipamento, tubulação, instalação e pintura, os fatores que influenciaram de forma mais significativa e direta no custo total de investimento. A ampliação da planta de um cenário para outro também acarreta em despesas associadas a contratação de funcionários e administração de todas as áreas da planta.

Neste trabalho não foram considerados os custos de depreciação e manutenção das peças por desgastes acarretados pela corrosão no Cenário 1. Estes fatores foram desprezados devido ao alto teor de ácido sulfídrico na composição inicial do biogás, que possuía uma concentração $65 \%$ maior do que limite suportado pela caldeira (1.000 ppm). Nestas condições, o processo corrosivo seria agravado em uma proporção que inviabilizaria o restante do processo. 


\section{Custo de operação}

Todo projeto requer um custo capital inicial e um custo de operação, sendo o primeiro responsável pela implantação da planta e o segundo por todos os gastos vinculados a seu funcionamento. A Tabela 9 ilustra os custos de operação associados aos dois cenários avaliados neste trabalho. A planta acoplada ao processo de purificação (Cenário 2) apresentou um custo de operação de US\$ 4.058.000,00 e enquanto a outra planta, US\$ 2.179.710,00, o que representa um aumento de 46\% entre elas. Nota-se que o Cenário 2 apresentou despesas maiores em todos os critérios, sendo a de maior influência o custo com utilidades, que pode ser justificado pela extensão da planta.

Tabela 9 - Custo de operação.

\begin{tabular}{|c|c|c|}
\hline & Cenário 1 (US\$/ano) & Cenário 2 (US\$/ano) \\
\hline Custos de Suporte da Planta & $525.960,00$ & $619.099,00$ \\
\hline Mão de Obra e Manutenção & $1.051 .920,00$ & $1.240 .000,00$ \\
\hline Geral e Administração & $174.377,000$ & $295.403,000$ \\
\hline Despesas de Operação & $208.193,00$ & $252.023,00$ \\
\hline Utilidades & $393.642,00$ & $1.580 .000,00$ \\
\hline Total & $2.179 .710,00$ & $4.058 .000,00$ \\
\hline
\end{tabular}

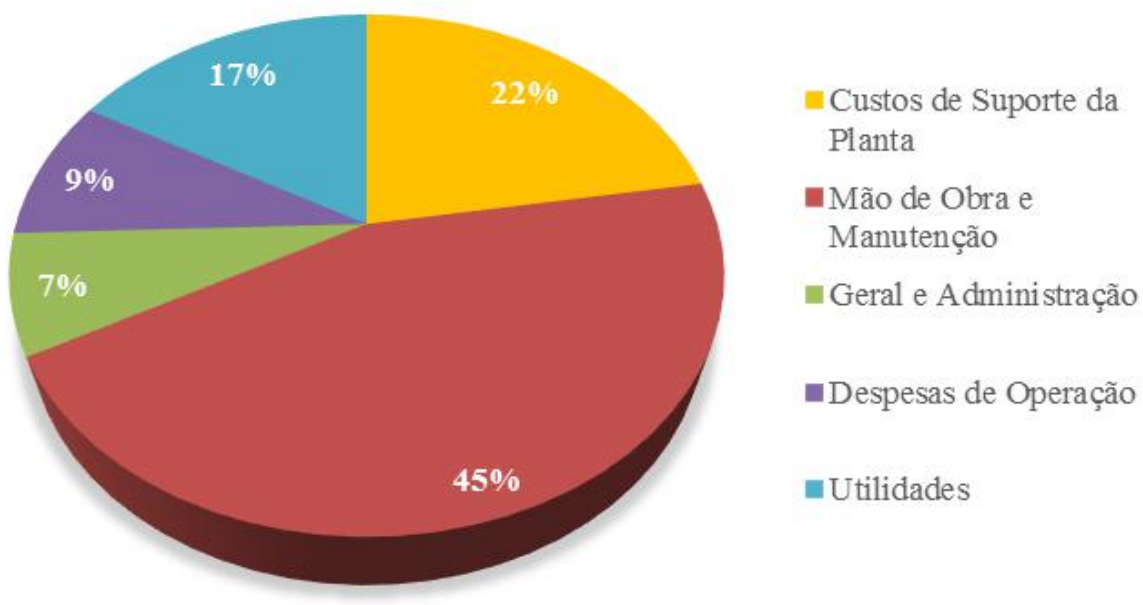

Figura 13 - Custos de operação do Cenário 1. 


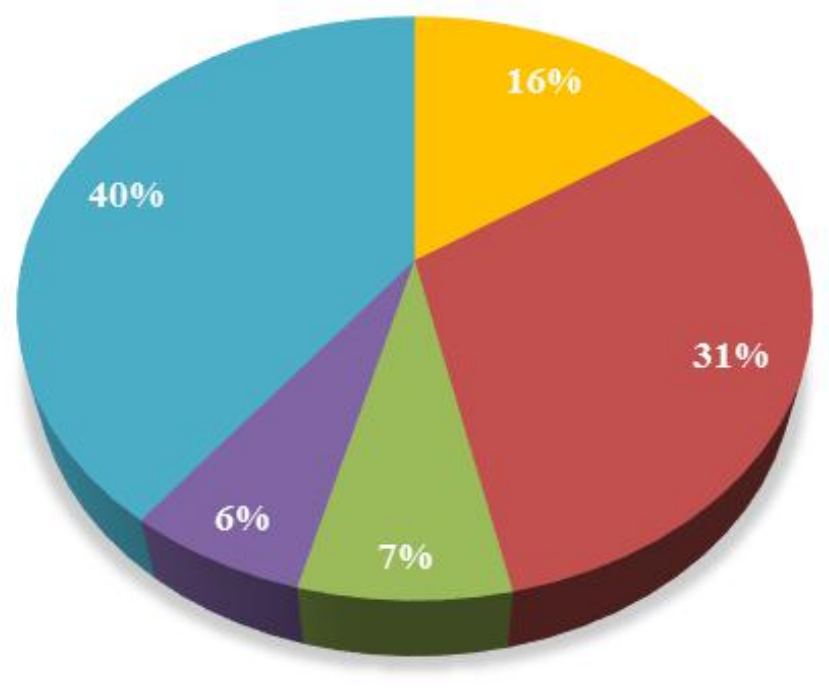

Custos de Suporte da Planta

- Mão de Obra e Manutenção

Eneral e Administração

- Despesas de Operação

- Utilidades

Figura 14 - Custos de operação do Cenário 2.

\section{$\underline{\text { Análise de custo }}$}

Análise de custo para a energia elétrica

O preço mínimo de venda (MSP) é o preço mais baixo que o produto pode ser oferecido no mercado tomando como base lucro zero. Para o cálculo do MSP, realiza-se uma análise de fluxo de caixa descontado, sendo necessário o custo capital total, o custo total anual de operação, a produção total de energia elétrica descontada da necessidade energética da ETE e o fator de recuperação de capital (CRF). A Equação (1) descreve o cálculo do CRF e a Equação (2) o cálculo do MSP.

$$
\begin{aligned}
& \text { CRF }=i * \frac{(1+i)^{n}}{\left[(1+i)^{n}-1\right]} \\
& M S P=\frac{(C R F * \text { Custo de Investimento Total }+ \text { Custo de Operaçẩo })}{\text { Produçầo Total de energia elétrica }(\text { KWh })}
\end{aligned}
$$

Na Equação (1) o termo " $n$ " representa o tempo de vida da planta e o termo "i" é a taxa de retorno desejada. Considerou-se o tempo de vida da planta como 20 anos e a taxa de retorno foi estabelecida como $10 \%$. Considerou-se também que o processo opera de forma contínua em estado estacionário como uma carga anual de 8760 horas. Na Tabela 10 encontram-se os valores calculados para o MSP (preço mínimo de venda) para os processos com e sem purificação. 
Tabela 10 - Valores de MSP referente a cada cenário.

\begin{tabular}{|c|c|}
\hline & MSP (US\$/KWh) \\
\hline Cenário 1 & 0,52 \\
\hline Cenário 2 & 6,79 \\
\hline
\end{tabular}

Observa-se que o valor do MSP da planta sem purificação (Cenário 1) é menor, o que condiz com as expectativas, uma vez que esse processo apresentou menor custo de investimento e operação. $O$ custo médio para energia elétrica no Brasil é de, aproximadamente, US\$ 0,16 por KWh (Sistema FIRJAN, 2017), valor é inferior aos valores de MSP encontrados. Sendo assim, seriam necessários subsídios governamentais para que os processos possam alcançar um preço de venda competitivo no mercado.

\section{CONCLUSÃO}

O objetivo da análise técnica e econômica foi alcançado, produzindo um ambiente de simulação condizente com a realidade. Em relação a parte energética, conclui-se que em todas as hipóteses consideradas para ambos os cenários, a quantidade de energia elétrica produzida foi suficiente para suprir as demandas da ETE e do processo de secagem do lodo, sendo ainda capaz de gerar um excedente de produção. Em relação ao Cenário 1, apesar de gerar grande excedente de energia, este não apresentou boas condições de funcionamento devido ao ácido sulfídrico circulante no processo. Adicionalmente, este Cenário é desfavorável em questões ambientais, devido à liberação de gases tóxicos para a atmosfera. $\mathrm{O}$ Cenário 2, por conter a etapa de purificação, não apresenta risco de deterioração da planta, assim como não representa um risco ambiental. Portanto, o Cenário 2, apesar de gerar menor excedente de energia, possui uma aplicabilidade maior do que o Cenário 1.

Os valores de preço mínimo de venda (MSP) encontrados foram superiores ao custo médio de comercialização de energia elétrica no Brasil. Nessas condições, nenhum dos dois cenários estudados apresentaram viabilidade financeira favorável. De modo geral, o estudo do aproveitamento energético do biogás gerado nas ETEs deve ser considerado como uma forma alternativa de suprir a demandas da sociedade a longo prazo, ainda que exijam investimentos governamentais mais altos. Trata-se de uma fonte de energia sustentável que tem grande potencial para tornar diversos processos industriais e cidades autossuficientes em termos energéticos. 


\section{REFERÊNCIAS}

BARREAU, A., BLANCHON LE BOUHELEC, E., HABCHI TOUNSI, K.N., MOUGIN, P., LECOMTE, F. Absorption of $\mathbf{H}_{2} \mathrm{~S}$ and $\mathrm{CO}_{2}$ in alkanolamine aqueous solution: Experimental data and modelling with the electrolyte-NRTL model. Oil and Gas Science and Technology 61, pp. 345-361, 2006.

BAUER, F., PERSSON, T., HULTEBERG, C., TAMM, D. Biogas Upgrading - Review of Commercial Technologies. SGC Rapport 2013:270, Swedish Gas Technology Center, Malmö, 2013.

CHAEMCHUEN, S., ZHOU, K., VERPOORT, F. From Biogas to Biofuel: Materials Used for Biogas Cleaning to Biomethane. Chembioeng Reviews, Wiley-Blackwell, [s.1.], v. 3 , n. 6 , pp. 250-265, 2016

COURTAUD, L., PEREGRINA, C., CREST, M., SABLAYROLlES, M.L., AUDIC, J. M., ARLABOSSE, P. Alternative fuels derived from organic waste: The case of sewage sludge characterization as a potential energy source. In: Proceedings of the $13^{\text {th }}$ International symposium on energy from biomass and waste, Venice, Italy. 2010.

DE SENA, R.F., CLAUDINO, A., MORETTI, K., BONFANTI, I.C., MOREIRA, R.F.P.M., JOSÉ, H.J. Biofuel application of biomass obtained from a meat industry wastewater plant through the flotation process - A case study. Resources Conservation and Recycling. 2007.

DEUBLEIN, D. STEINHAUSER, A. Biogas from waste and renewable resources: An introduction. Wiley-V CH, Weinheim, pp. 7-23, 2008.

DIAS, M. O. S. Desenvolvimento e otimização de processos de produção de etanol de primeira e segunda geração e eletricidade a partir da cana-de-açúcar. 2011. 253 f. Tese (Doutorado em Engenharia Química) - Universidade Estadual de Campinas, Campinas. 2011.

ELFATTAH, T.A., ELDRAINY, Y.A., ATTIA, A. Utilization of Aspen HYSYS simulation to determine the optimum absorber working pressure needed to achieve more than 0.99 methane purity. International Journal of Information Research and Review, v.3, pp. 1739-1744, 2016.

EUROPEAN COMMISSION. Environmental pressure indicators for the EU. Office for official publications of the European Communities. Luxembourg. 2001.

FONSECA, A. R., GOMES, M. L. A. C. N. Eficiência energética e a queima de combustíveis limpos. 2009. 89 f. Tese (Mestrado em Engenharia Química) - Instituto Superior de Engenharia do Porto, Politécnico do Porto, Porto. 2009. 
FONTS, I., AZURA, M., GEA, G., MURILLO, M.B. Study of the pyrolysis liquids obtained from different sewage sludge. Journal of Analytical and Applied Pyrolysis, v. 85, pp. 184-191, 2009.

GUZMAN MERCADO, A. Remoção de sulfeto de hidrogênio de biogás em instalação piloto com óxido de ferro. 2010. 1124p. Dissertação (Mestrado em Engenharia Ambiental) - Universidade Federal de Santa Catarina, Florianópolis, 2010.

HAMAGUCHI, M., VAKKILAINEN, E. Corrosão em tubos de superaquecedor de caldeiras de recuperação: um desafio. Revista O Papel, v. 71, nº 6, pp. 57-71, 2010.

LOUREIRO, J. M., KARTEL, M. T. Combined and Hybrid Adsorbents: Fundamentals and Applications. Springer Science \& Business Media, Heidelberg, 2006.

METCALF E EDDY. Wastewater Engineering Treatment Disposal Reuse. 4. ed. New York, McGraw - Hill Book, 1815p. 2003.

NOYOLA, A., MORGAN-SAGASTUME, J.M., LÓPEZ-HERNÁNDEZ, J.E. Treatment of biogas produced in anaerobic reactors for domestic wastewater: Odor control and energy/resource recovery. Reviews in Environmental Science and Biotechnology 5, pp. 93-114, 2006.

ROSA, A.P., LOBATO, L.C. DA S., BORGES, J.M., MELO, G.C.B., CHERNICHARO, C.A. L. Potencial energético e alternativas para o aproveitamento do biogás e lodo de reatores UASB: estudo de caso Estação de tratamento de efluentes Laboreaux (Itabira). Engenharia Sanitária e Ambiental 21, pp. 315-328, 2016.

RYCKEBOSCH, E., DROUILLON, M., VERVAEREN, H. Techniques for transformation of biogas to biomethane. Biomass and Bioenergy 35, pp. 1633-1645, 2011.

SIRCAR, S. Basic Research Needs for Design of Adsorptive Gas Separation Processes. Ind. Eng. Chem. Res., v. 45 (16), pp. 5435-5448, 2006.

SISTEMA FIRJAN. Pesquisa e Estudos Econômicos: Ambiente de Negócios. Rio de Janeiro: Sistema Firjan, 2017. Disponível em: http://www.firjan.com.br, consultado em junho de 2017.

SISTEMA NACIONAL DE INFORMAÇÕES SOBRE SANEAMENTO - SNIS. Diagnóstico dos serviços de água e esgotos. Site institucional, 2017. Disponível em: http://www.snis.gov.br, consultado em maio de 2017.

TOCK, L., GASSNER, M., MARÉCHAL, F. Thermochemical production of liquid fuels from biomass: Thermo-economic modeling, process design and process integration analysis. Biomass Bioenergy, v. 34 (12), pp. 1838-1854, 2010.

VAIDYA, P. D., KENIG, E. Y. $\mathrm{CO}_{2}$-alkanolamine reaction kinetics: A review of recent studies. Chem. Eng. Technol, v. 30 (11), pp. 1467-1474, 2007. 
YANG, R. T. Adsorbents: Fundamentals and Applications. John Wiley \& Sons, Hoboken, 2003.

ZARE ALIABAD, H., MIRAZEI, S. Removal of $\mathrm{CO}_{2}$ and $\mathrm{H}_{2} \mathrm{~S}$ using Aqueous Alkanolamine solutions. World Academy of Science, Engineering and Technology, v. 49, pp. 51-59, 2009 . 